Andrew B. Cooper ṂD FRCPC, Michael D. Sharpe MD FRCPC

\title{
Bacterial meningitis and cauda equina syndrome after epidural steroid injections
}

\begin{abstract}
Purpose: To describe a rare adverse outcome resulting from lumbar epidural steroid injections for the treatment of chronic lower back pain.

Clinical features: We report a case of staphylococcus aureus meningitis and cauda equina syndrome following a series of epidural steroid injections for chronic back pain. Although rare, bacterial meningitis following epidural analgesia has been reported, but epidural steroid injections have not been associated with either bacterial meningitis or cauda equina syndrome. The causal relationship between epidural steroid injections, bacterial meningitis, and cauda equina syndrome is discussed.

Conclusion: A thorough pre-procedure assessment with attention to the neurologic examination and signs/symptoms of infection is essential.
\end{abstract}

Objectif: Décrire une complication rare survenue à la suite d'injections épidurales lombaires de stéroïdes pour le traitement d'une lombalgie chronique.

Caractéristiques cliniques: Une méningite à staphylocoque doré accompagnée d'un syndrome de la queue de cheval est apparue à la suite d'une série d'injections épidurales de stéroïdes administrées pour traiter une lombalgie chronique. Quoique rare, la méningite bactérienne a déjà été rapporté à la suite d'une épidurale mais les stéroïdes épiduraux n'ont jamais été associés à une méningite bactérienne et au syndrome de la queue de cheval. La relation causale entre les

\section{Key words}

ANAESTHETIC TECHNIQUES: epidural;

COMPLICATIONS: bacterial meningitis, cauda equina syndrome.

From the Department of Anaesthesia, University Hospital and Program in Critical Carc Medicine, University of Western Ontario, London, Ontario, N6A 5A5.

Address correspondence to: Dr. Michael D. Sharpe,

Department of Anaesthesia, University Hospital, 339

Windermere Road, London, Ontario N6A 5A5.

Phone: 519-663-3282, Fax: 519-663-3079.

email:mdsharpe@julian.uwo.ca

Accepted for publication 25th January, 1996. injections épidurales de stéroïdes, la méningite bactérienne et le syndrome de la queue de cheval est discutée.

Conclusion: Avant de réaliser la technique épidurale, il est essentiel de procéder à un examen neurologique et de rechercher les signes et les symptômës d'une infection.

Major complications following epidural anaesthesia and analgesia are rare and the average practitioner is unlikely to encounter one in his/her career.' Bromage ${ }^{2}$ recommended that a scrupulously vigilant approach to such complications is useful in decreasing serious morbidity. We present a case in which severe complications followed a series of epidural steroid injections for chronic back pain and explore the possible reasons for the outcomes encountered.

\section{Case report}

A 71-yr-old man with a history of complex partial seizure disorder, coronary artery bypass grafting, peripheral vascular disease and prostatism was treated for chronic lower back pain with an epidural injection of lidocaine $0.5 \%$ and $80 \mathrm{mg}$ depomedrol, one month before admission. He reported good relief from pain and, one week later, received a second injection which did not achieve as good a result. Three days after the second injection he reported an increase in his lower back pain, accompanied by chills and profuse sweating. He was seen at his local hospital two days after the development of these symptoms and was discharged following examination and blood cultures. No antibiotic therapy was begun at that time. Continuing to have back pain, he received his third injection one week after the second. His temperature at the time of the procedure was $38.7^{\circ} \mathrm{C}$. Later the same day he was admitted to hospital; blood cultures taken during the previous emergency room visit were positive for Staphylococcus aureus. Physical examination was unremarkable apart from localized tenderness at the $\mathrm{L}_{5}-\mathrm{S}_{1}$ intervertebral space. WBC count was $6.8 \times 10^{9} \cdot \mathrm{L}^{-1} ; 79 \%$ neutrophils, $14 \%$ band forms stabs and $7 \%$ lymphocytes. Broad spectrum antibiotic coverage was begun. The following 


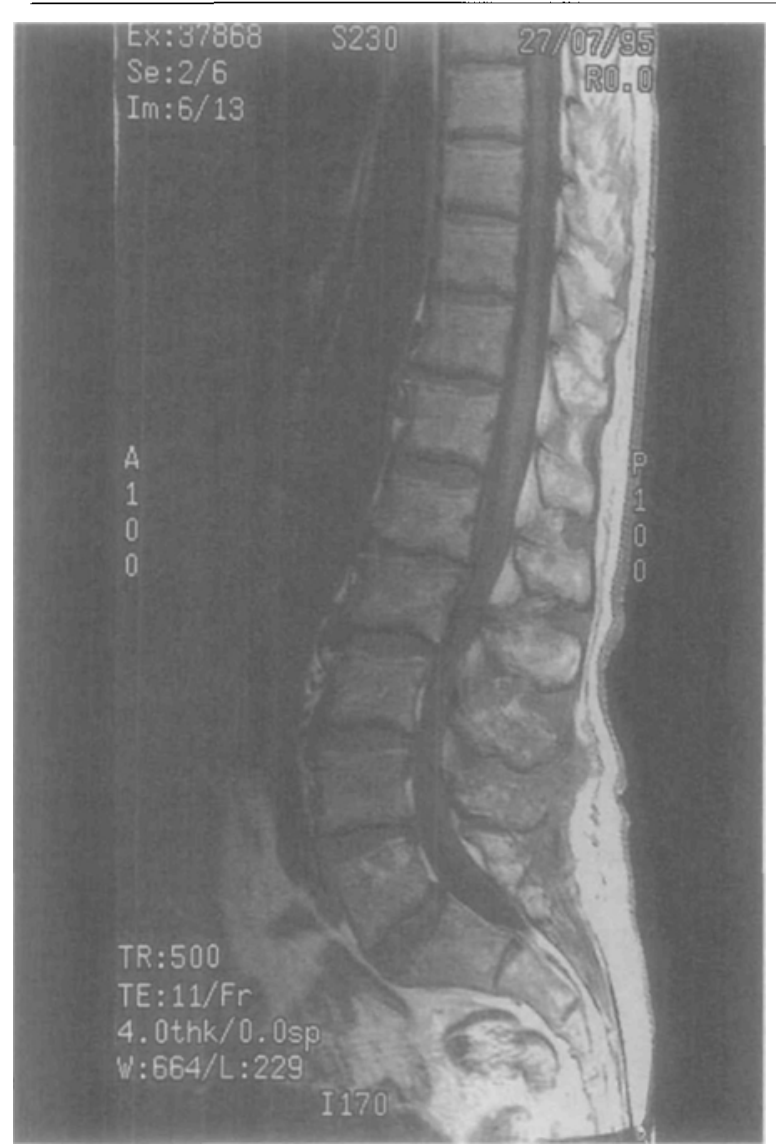

FIGURE 1 MRI spine: Sagittal view pre contrast (gadolinium) from $T_{7}$ to $S_{3}$ vertebral levels.

day, a CT scan revealed annular bulging of the intervertebral discs from $L_{2}$ to $S_{1}$, soft tissue emphysema consistent with the previous epidural procedures, but no evidence of epidural abscess. A lumbar puncture was performed and the cytocentrifuged specimen of CSF demonstrated $1+$ polymorphonuclear cells on gram stain but no bacteria. The cell count was $300 \times 10^{6} \cdot \mathrm{L}^{-1}$ WBC's $22 \%$ polymorphonuclear cells, $78 \%$ mononuclear cells), tuberculosis and fungal studies were negative. Staphylococcus aureus sensitive to cloxacillin was subsequently cultured and treatment was revised to cloxacillin $4 \mathrm{~g}$ iv $\mathrm{q} 6 \mathrm{~h}$. On the thirteenth hospital day he began to complain of weakness in his left leg and he became incontinent of stool. He was then transferred to our tertiary care hospital for consultation. Neurological examination at that time revealed mildly decreased power in the left lower extremity, decreased light touch sensation in the $L_{4,5}$ and $S_{1}$ dermatomes and hyperaesthesia to pinprick. There was decreased pinprick sensation in the $L_{5}, S_{1}$ and $S_{2}$ dermatomes on the perineum. He was noted to be incontinent of stool and the anal

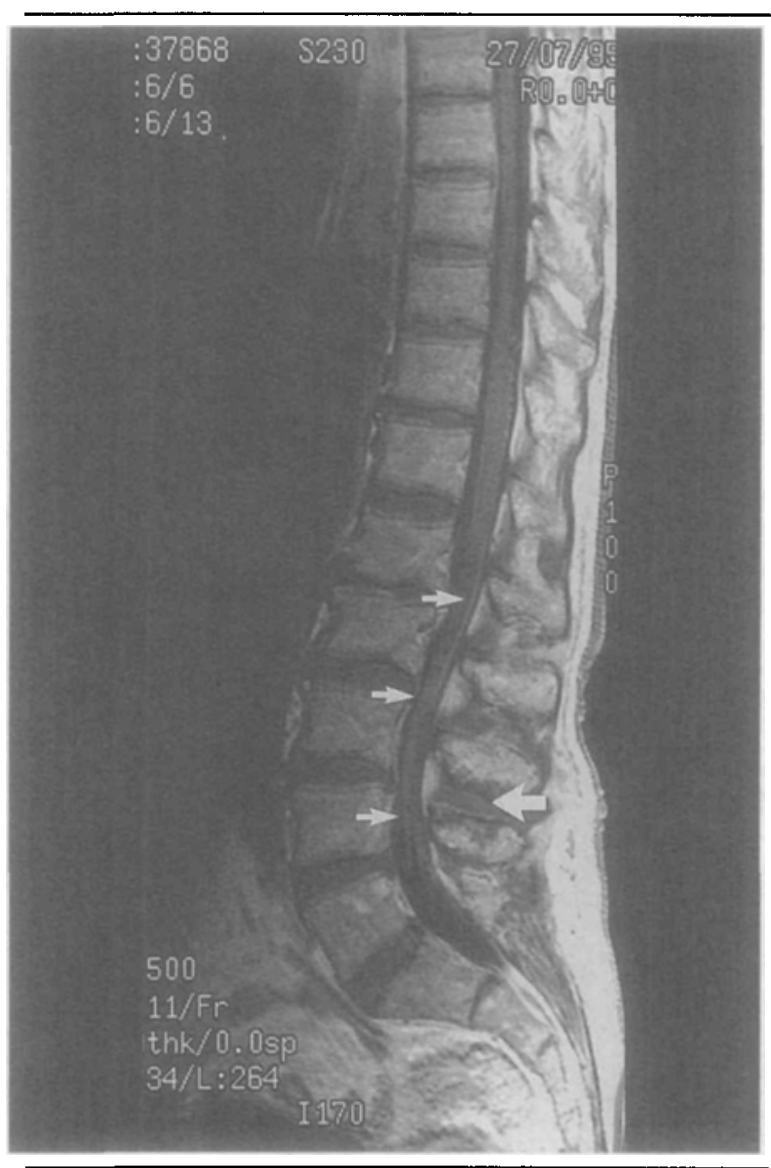

FIGURE 2 MRI spine: Sagittal view post contrast (gadolinium) from $T_{7}$ to $S_{3}$ vertebral levels. (a) small arrows indicate enhancement of the cauda equina, (b) large arrow identifies the $L_{3-4}$ interspace.

sphincter tone was decreased. A repeat CSF specimen had a glucose concentration of $3.7 \mathrm{mmol} \cdot \mathrm{L}^{-1}$, a protein of $1.058 \mathrm{~g} \cdot \mathrm{L}^{-1}$, and WBC count of $158 \times 10^{6} \cdot \mathrm{L}^{-1}(42 \%$ polymorphonuclears, $58 \%$ mononuclears). The MRI revealed a right posterolateral disc protrusion at $\mathrm{L}_{1-2}$ below the level of the conus medullaris and a small central disc protrusion not affecting the roots at $\mathrm{L}_{4-5}$. An epidural abscess or haematoma was not present; however, there was contrast (gadolinium) enhancement in the conus medullaris and cauda equina which is consistent with inflammation of these structures. (see Figures 1 and 2) A transthoracic echocardiogram showed no evidence of bacterial endocarditis. Antibiotic treatment was continued until the twenty-third hospital day. The patient's leg weakness had improved but he was still unable to sense rectal fullness and stool incontinence continued. The patient was discharged for rehabilitation on the twenty eighth hospital day; discharge diagnoses were Staphylococcus aureus meningitis and cauda equina syndrome. 


\section{Discussion}

There were several perplexing questions regarding this patient's illness: (1) What was the cause of the bacteraemia and meningitis? (2) Could the epidural steroid injections have predisposed to meningitis? and (3) What was the cause of the cauda equina syndrome?

Staphylococcus aureus meningitis is a rare disease, accounting for only $1-9 \%$ of all cases of meningitis. Jensen et al. ${ }^{3}$ in their series of 104 cases noted that postoperative meningitis $(59 \%)$ was more common than haematogenous meningitis $(41 \%)$. Epidural catheters were used in only $13 \%$ of cases. In haematogenous meningitis, the most common portal of entry was the skin, although in over half of cases, no portal of entry was identified. Case reports of meningitis following epidural analgesia are rare. Ready ${ }^{4}$ reported two parturients, one of whom had bacteraemia, vaginal colonization and meningitis with Streptococcus uberis, while the other had cellulitis at the epidural catheter site and Streptococcus faecalis meningitis. Ania ${ }^{5}$ reported a patient whose epidural tip and CSF yielded Staphylococcus aureus. In our patient, the presence of fever and the demonstration of positive blood cultures two days before the third epidural injection may have indicated that meningitis was already present.

The pathophysiological sequence of bacterial meningitis $^{6}$ involves colonisation or mucosal invasion, intravascular survival, crossing of the blood brain barrier and survival within the CSF. Of these, the factors governing the crossing of the blood brain barrier are least understood. We propose that bacteraemia was caused by translocation of Staphylococcus aureus from the skin during the epidural procedure , and that meningitis resulted through haematogenous dissemination of bacteria. It is also possible that infection was introduced into the epidural, subdural or subarachnoid space by the epidural needle, catheter or injectate. These mechanisms have been proposed in other case reports of meningitis following epidural anaesthesia and lumbar puncture ${ }^{8,9}$ The possibility of migration of an epidural catheter into the subdural or subarachnoid space should also be kept in mind; its incidence being estimated at approximately $6 \%$ in one series. $^{9}$

Immuno suppression caused by glucocorticoids is due to the disruption of intercellular communication among leukocytes through interference with production or function of lymphocytokines. ${ }^{10}$ Case reports underscore the association between steroid administration in the epidural space and the development of infectious complications. Elliott ${ }^{11}$ and Goucke and Graziotti ${ }^{12}$ describe patients receiving steroid injections for chronic lower back pain, with subsequent septicaemia or epidural abscess. Bromage's review of ten earlier case reports of epidural abscess ${ }^{2}$ details epidural steroid administration in four and systemic steroid in two of the patients. We speculate that epidural steroid administration may have predisposed our patient to infection of the CSF with Staphylococcus aureus by attenuation of host defences.

Cauda equina syndrome results from injury to the sacral nerve roots and is characterized by varying degrees of bowel and bladder dysfunction, loss of perineal sensation and lower extremity motor weakness. Case reports have highlighted an association with subarachnoid anaesthesia. ${ }^{13-16}$ In three cases, attempted epidural anaesthesia is described, but there was uncertainty about the location of the epidural catheter, or the catheter was clearly demonstrated to have migrated into the subdural or subarachnoid space. High volumes of local anaesthetic or hypertonic solutions (bicarbonate for $\mathrm{pH}$ adjustment) were postulated causative factors in these cases. Lidocaine can produce a concentration dependent irreversible conduction block in frog sciatic nerve. ${ }^{17}$ This and other studies support the contention that exposure of nerves to high, localized concentration of lidocaine over prolonged periods is a possible explanation for Cauda Equina Syndrome in these case reports. However, the blocks our patient received did not contain high concentration lidocaine doses or hypertonic preparations. Furthermore, in contrast to the above reports, Cauda Equina Syndrome developed in our patient as a late (instead of early) complication. It seems likely that meningitis was the causative factor in our patient which was supported by the MRI finding of contrast enhancement in the cauda equina. Experimental meningitis produces neural oedema, ${ }^{16}$ which may be vasogenic (due to changes in vascular permeability), or cytotoxic (due to toxins released by bacteria or neutrophils). Furthermore, our patient had documented peripheral vascular disease and therefore may have been susceptible to reduced cord perfusion. One may speculate that the complication developed as a result of ischaemia ensuing from meningitis, or the direct effects of inflammation on the cauda equina and conus medullaris.

We conclude that Staphylococcus aureus meningitis is a rare complication of epidural analgesia, which may develop as a result of bacteraemia or operative contamination of the epidural space. The role of epidural steroid in such a setting may be seen as a predisposing factor as a result of local immunosuppression. The aetiology of Cauda Equina Syndrome in our patient remains uncertain although the role of neural ischaemia as a result of meningitis is possible. The development of such severe morbidity following a procedure whose indication was relief of moderate chronic discomfort emphasizes the importance of obtaining informed consent with disclo- 
sure of rare complications, such as those described here. A thorough preoperative assessment with attention to the neurological examination and symptoms of infection is essential.

\section{References}

1 Cousins MJ, Bridenbaugh PO. Complications of epidural blockade, In: Neural Blockade in Clinical Anesthesia and Management of Pain, 2nd ed. Philadelphia: JB Lippincott Company, 1988: 340.

2 Bromage PR. Spinal extradural abscess: pursuit of vigilance. Br J Anaesth 1993; 70: 471-3.

3 Jensen $A G$, Espersen F, Skinhoj P, Rosdahl VT, FrimodtMoller $N$. Staphylococcus aureus meningitis. A review of 104 nationwide, consecutive cases. Arch Intern Med 1993; 153: 1902-8.

4 Ready $L B$, Helfer $D$. Bacterial meningitis in parturients after epidural anesthesia. Anesthesiology 1989; 71 : 988-90.

5 Ania BJ. Staphylococcus aureus meningitis after shortterm epidural analgesia. Clin Infect Dis 1994; 18: 844-5.

6 Quagliarello V. Scheld WM. Bacterial meningitis: pathogenesis, pathophysiology, and progress. N Engl J Med 1992; 327: 864-72.

7 Domingo P, Mancebo J, Blanch L, Coll P, Martinez E. latrogenic streptococcal meningitis (Letter). Clin Infect Dis 1994; 19: 356-7.

8 Harding SA, Collis RE, Morgan BM. Meningitis after combined spinal-extradural anaesthesia in obstetrics. $\mathrm{Br} J$ Anaesth 1994; 73: 545-7.

9 de Leon-Casasola OA, Myers DP, Rempel J, et al. A prospective analysis of epidural migration in 1598 surgical cancer patients. Anesthesiology 1991; 75: A730.

10 Gilman AG, Rall TW, Nies AS, Taylor P. Adrenocortical steroids, In: Goodman and Gilman's The Pharmacological Basis of Therapeutics, 8th ed. Toronto: Pergamon Press, 1990: 1443-5.

11 Elliott RH, Collett BJ. Delayed septicaemia after extradural steroid treatment (Leter). Br J Anaesth 1992; 69: 422-3.

12 Goucke $C R$, Graziotti P. Extradural abscess following local anaesthetic and steroid injection for chronic low back pain. Br J Anaesth 1990; 65: 427-9.

13 Rigler ML. Drasner K, Krejcie TC, et al. Cauda equina syndrome after continuous spinal anesthesia. Anesth Analg 1991; 72: 275-81.

14 Cheng $A C$. Intended epidural anesthesia as possible cause of cauda cquina syndrome. Anesth Analg 1994; 78: 157-9.

15 Drasner K, Rigler ML, Sessier DI, Stoller ML. Cauda equina syndrome following intended epidural anesthesia. Anesthesiology 1992: 77; 582-5.

16 Ackerman WE III, Andrews PJ, Juneja MM, Rigor BM. Cauda equina syndrome: a consequence of lumbar disk protrusion or continuous subarachnoid analgesia? Ancsth Analg 1993; 76: 898-901.

17 Bainton CR, Strichartz GR. Concentration dependence of lidocaine-induced irreversible conduction loss in frog nerve. Anesthesiology 1994; 81: 657-67. 